\title{
Contaminación ambiental por basurales
}

\author{
C.H. Colangelo
}

Facultad de Ciencias Exactas y Naturales y Facultad de Informática, Ciencias de la Comunicación y Técnicas Especiales. Universidad de Morón.

E-mail: toxicolangelo@gmail.com / ccolangelo@unimoron.edu.ar

\section{Resumen}

Es común observar en diferentes regiones del país, la presencia de basurales a cielo abierto, de los cuales generalmente el común de la gente se pregunta si estos pueden constituir una fuente múltiple de suma importancia en la contribución de factores de contaminación ambiental. En este trabajo se hace referencia de los principales componentes de afectación ambiental que pueden contribuir a la contaminación ambiental, como ser: gases de efecto invernadero (metano -además altamente inflamabledióxido de carbono) - benceno (reconocido agente de acción cancerígena) - olores (de diferente origen) - metales pesados (en suelos y de diferente naturaleza tal como por ejemplo las pilas y baterías) - agentes químicos variados (que pueden llegar a producir contaminación del agua) agresión sonora (por movimientos vehiculares de transporte en zonas del basural y aledaños) - contaminación por lixiviados (no contenidos adecuadamente), presencia de residuos peligrosos y patogénicos y otros aspectos de suma importancia como la salud ocupacional (por trabajo informal) - enfermedades (hepatitis, toxoplasmosis, fiebre tifoidea y poliomelitis, al igual que otras patologías como las broncopulmonares), afectación de actividades regionales; ubicación de los basurales en zonas inundables, etc.,etc. A pesar de todo lo señalado, es posible tomar acciones correctivas para evitar el daño al ambiente, algunas como reciclado de materiales, uso de los gases generados en el basural y otras medidas que contribuyen a la disminución del problema planteado. Como conclusión podemos señalar que en post-clausura en los vertederos de Residuos Sólidos Urbanos (RSU), y la gravedad de la deposición clandestina de residuos, como también la falta muchas veces de un control post-cierre, son estos factores que contribuyen a la imposibilidad de lograr un efectivo control ambiental por este tipo de emprendimientos.

Palabras clave: ambiente, contaminación ambiental, basurales

\section{Introducción}

En la actualidad, el mundo produce alrededor de 1.500 millones de toneladas anuales de residuos, en donde ese volumen aporta casi el $5 \%$ de las emisiones de gases de efectos invernadero. Estos están conformados principalmente por metano y dióxido de carbón.

En Argentina, el promedio diario de desechos por habitante es de 1,03 kilogramos, equivalentes a 45.000 toneladas diarias para toda la población (una tonelada cada 2 segundos) y alrededor de 16,5 millones de toneladas por año.

Vemos que, con esos datos, la magnitud del volumen de residuo, que es de significativa importancia, y que debe ser llevada a cabo con los cuidaos que el medio ambiente necesita.

En esta contribución se enumerará y hará una breve descripción de los problemas ambientales que provocan los basurales. 
Un basural se puede describir como un reactor bioquímico el primero constituido por basura y agua y la segunda por que tiene dos grandes flujos: uno de entrada y otro de salida, gases y lixiviados (Fig. 1).

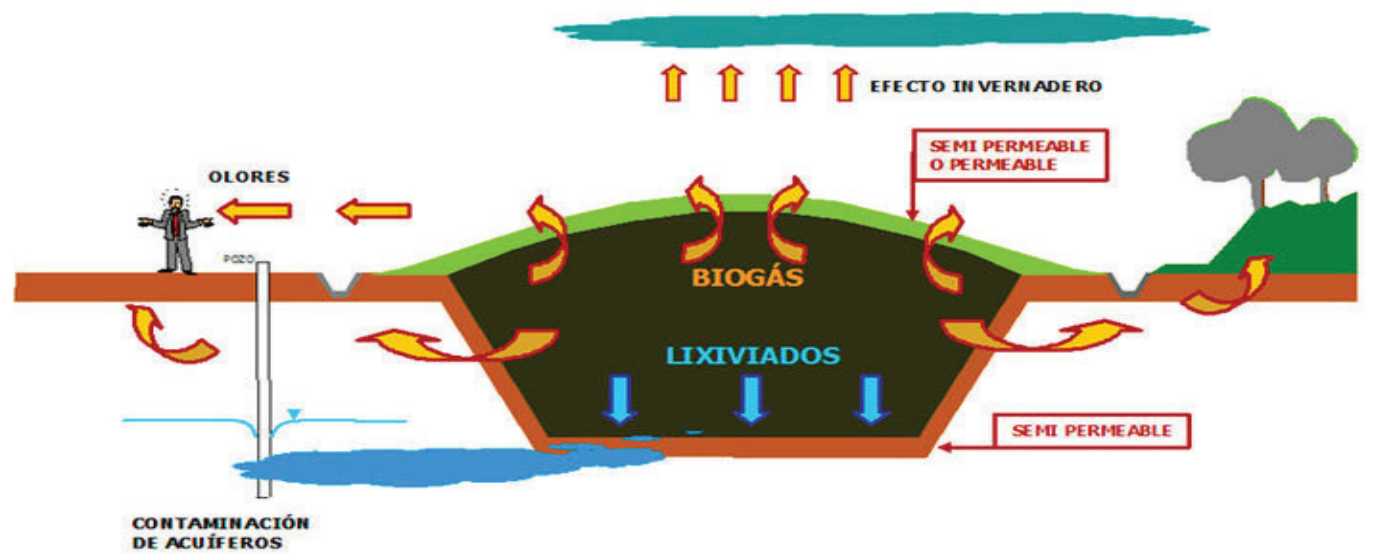

Figura 1 - Corte de un Basural.

Cuando los basurales son construidos con pautas no adecuadas, como marcan algunas normativas y principios de ingeniería, ocurren los graves problemas ambientales, que pasaremos a describir a continuación y que han sido moneda corriente en la observación y detección del autor en su actuar profesional como Perito Químico Oficial en la Suprema Corte de Justicia de la Provincia de Buenos Aires.

\section{Problemas ambientales detectados}

1- Gases/ Vapores. Los basurales emiten gases, existiendo diferentes etapas en la producción de los mismos, cuya explicación exceden los alcances de la presente contribución (1).

Los gases más importantes están constituidos por metano y dióxido de carbón, los cuales son denominados gases de efecto invernadero, y que en los basurales no son empleados en ninguna forma, siendo dispersados al ambiente.

Otros componentes de destacar, lo es el benceno, cloruro de vinilo y el sulfuro de hidrógeno, siendo los dos primeros, agentes de comprobada acción carcinogénica en el hombre y clasificada como tal por organismos como IARC (International Agency for Research on Cancer) (2) (3), entre otros. El tercer agente citado, tiene una clara acción irritante.

2- Metales. Se han detectado metales pesados (principalmente en suelos, provenientes de materiales descartados de diferente naturaleza tal como por ejemplo las pilas y baterías), con el aporte de metales pesados tales como: plomo - mercurio - zinc - cadmio y níquel.

3- Agentes químicos variados. Agentes químicos diversos que pueden llegar a producir contaminación del agua y del suelo, aquí la variabilidad de productos que pueden encontrarse es muy amplia. Se ha observado en muchos basurales que por ejemplo no existía respecto del agua subterránea y superficial, una red de monitoreo (4) por lo cual no había control de la contaminación.

4- Agresión sonora y otros (por movimientos vehiculares de transporte en zonas del basural y aledaños). En este sentido provocado por los vehículos que transportan residuos y ordenan los mismos sobre la superficie del predio. Es posible también que se generen graves accidentes con las personas que realizan los trabajos informales en la superficie del basural.

5- Contaminación por lixiviados. Existe una amplia variedad en las formas en que se lleva a cabo la disposición de la basura. La composición de los propios residuos sólidos varía sustancialmente de lugar en lugar, además de cambiar las condiciones climáticas y ambientales.

El lixiviado se genera como consecuencia de la humedad de la basura y la infiltración y percolación de parte de las 
precipitaciones pluviales.

Los lixiviados (5) poseen entre otros: alta carga orgánica, pH ácido y cargas bacterianas diversas.

6- Presencia de residuos patogénicos. Estos residuos deben seguir en origen, los lineamientos de la normativa correspondiente (por ejemplo: Ley 11.347 y Decreto 450/94, en Provincia de Buenos Aires). Es común ver estos tipos de residuos en basurales.

7- Residuos Peligrosos. Los mismos deben seguir la ruta indicada por la Ley 24.051 (Residuos Peligrosos) 0 11.720 (Residuos Especiales- Prov Buenos Aires), según el ámbito de aplicación.

8- Otros aspectos. Otras cuestiones de suma importancia como la salud ocupacional (por trabajo informal) - enfermedades (hepatitis, toxoplasmosis, fiebre tifoidea y poliomelitis), al igual que otras patologías como las broncopulmonares, también son de ocurrencia frecuente en los basurales.

Se ha podido observar también falta de vallado perimetral, que permite el ingreso irrestricto al predio, lo que permite el desarrollo de actividades laborales informales.

Puede sumarse a la lista anterior, la afectación de actividades regionales por contaminación en campos cultivos, ingesta de bolsas en caballos en Aras vecinas al predio, presencia de humos en rutas (por quema de basura, con generación de accidentes de tránsito por disminución de la visibilidad), degradación visual paisajística (6), fuente de vectores de enfermedades varias que no se combaten en el Basural.

Se ha visto la ubicación de los basurales en zonas inundables, como también la presencia de geomembranas sin uso eficaz de su incorporación, que es la contención de los lixiviados.

\section{Algunas medidas de solución}

Los lixiviados (7) pueden ser tratados para disminuir la carga bacteriana y la alta carga orgánica que estos poseen. En algunos países es de práctica, proceder a la utilización de los gases emitidos, con inyección al sistema de distribución de gas de línea o emplearlo en el propio predio para generación de electricidad (8).

Algunos municipios, formalizan la mano de obra in situ, desarrollando emprendimientos para la clasificación de los residuos y obtener así productos como papel, cartón, plásticos, metales varios para la venta al mercado.

Otro aspecto significativo, es el control post-cierre de los basurales, cuando éstos llegan al fin de su vida útil de almacenamiento, donde el control adecuado de la Agencias Ambientales, es primordial para el cuidado ambiental.

El tema es mucho más amplio de tratar, y que no se agota en este aporte. Son varios los interpretes que deben sumarse a la acción para paliar y controlar las afectaciones ambientales que los basurales sin control provocan al medio ambiente.

\section{Referencias Bibliográficas}

(1) Colangelo, C.H. (2011): "Impacto de un relleno sanitario urbano sobre aguas, suelos y vegetales comestibles" (Tesis doctoral) - Universidad de Morón - Buenos Aires - Argentina

(2) IARC (1982). Some industrial chemicals and dyestuffs. IARC Monogr Eval Carcinog Risk Chem Hum, 29: 1-398. PMID:6957379

(3) IARC (1979). Some monomers, plastics and synthetic elastomers, and acrolein.IARC Monogr Eval Carcinog Risk Chem Hum, 19: 1-513. PMID:285915

(4) Resolución No 1143/02. Disposición de Residuos Sólidos Urbanos en Rellenos Sanitarios - Organismo Provincial para el Desarrollo Sostenible. Recuperado de: $\quad$ http://www.opds.gba.gov.ar/sites/default/files/ RESOLUCION\%201143\%2002.pdf

(5) Álvarez Contreras, A., \& Suárez Gelvez, J. H. (2006). Tratamiento biológico del lixiviado generado en el relleno sanitario" El Guayabal. Ingeniería y Desarrollo, (20).

(6) Francisca, F. M., \& Vettorazzi, M. (2002, November). Disminución de la calidad ambiental debido al vertido no controlado y abandono de depósitos de residuos. XVI Congreso Anual de Mecánica de Suelos e Ingeniería Geotécnica.

(7) Giraldo, E. (2001). Tratamiento de lixiviados de rellenos sanitarios: avances recientes. Revista de ingeniería, (14), 44-55.

(8) Asís, H., Dopazo, F., \& Gianoglio, P. (2006). Producción de energía a partir de biogás obtenido de residuos sólidos urbanos. 